\title{
The Base Composition of Deoxyribonucleic Acids of Streptomyces
}

\author{
By CLARA FRONTALI \\ Laboratorio di Fisica, Istituto Superiore di Sanità, Rome, Italy \\ L. R. HILL AND L. G. SILVESTRI \\ Progetto Sistematica Actinomiceti, Università Statale, Milano 4, Italy
}

(Received 10 August 1964)

SUMMARY

The base composition of DNA preparations from 12 strains of Streptomyces and 1 strain of Nocardia were determined from their denaturation temperature $\left(T_{m}\right)$ and buoyant density.

The \% GC (guanine + cytosine) contents ranged from 74.4 to 78.5 (from $T_{m}$ ) and from 69.4 to 73.4 (from buoyant density). The correlation between the two sets of data and the found differences are discussed. The range of pH values which did not affect $T_{m}$ and the degree of hyperchromic effect have been related to the ionic strength of the solvent. With $0.01 \mathrm{M}$-phosphate as solvent the $\mathrm{pH}$ indifference range was narrower and the hyperchromic effect smaller than with $0 \cdot 2 \mathrm{M}-\mathrm{Na}^{+}$solvent.

Though the difference between the maximum and minimum $\% \mathrm{GC}$ in Streptomyces is sufficient to distinguish the respective strains, within the extreme values there is a continuous progression of base composition which does not permit taxonomic divisions to be made on the basis of overall $\%$ GC alone.

\section{INTRODUCTION}

The base composition of bacterial DNA, expressed as \% GC (guanine + cytosine), varies widely from one genus to another, but, generally, very little from one species to another in the same genus (Lee, Wahl \& Barbu, 1956; Belozersky \& Spirin, 1960; Marmur, Falkow \& Mandel, 1963). The DNA from any one strain is, however, very homogeneous in base composition, as shown by its narrow banding in caesium chloride density gradient ultracentrifugation, the narrow range of temperature over which it denatures, and its readiness to 'renature' under suitable cooling conditions. Close genetic relationship can be indicated by the formation in vitro of hybrid DNA molecules in which the two strands originate from different DNAs. To enable the formation of such hybrids, the two parent DNAs should have, as a first requirement, the same overall base composition and, as a second requirement, similar base sequences, which, in turn, imply similar genetic information, since the latter is held to be coded in the DNA precisely in the sequences of the four bases, guanine (G), cytosine (C), adenine (A), thymine (T). Therefore, we thought it opportune as a first step to determine the base composition of DNAs from strains of Streptomyces and Nocardia that had been included in a previous phenetic classification (Silvestri, Turri, Hill \& Gilardi, 1962). For this purpose, two techniques were used: $(a)$ to determine for each DNA sample the 'melting temperature' $\left(\boldsymbol{T}_{m}\right)$, which, according 
to Marmur \& Doty (1962), is linearly related to \% GC; $(b)$ to determine the buoyant density of the samples in $\mathrm{CsCl}$ gradient centrifugation, which according to Schildkraut, Marmur \& Doty (1962) is again linearly related to \% GC.

\section{METHODS}

Organisms. The strains of Streptomyces and Nocardia used were selected from those comprised in the study by Silvestri et al. (1962) according to three criteria: (a) that they were located in different spheres (or phenetic taxa) in the earlier phenetic classification; $(b)$ that they were as near as possible to the respective geometrical centres of their spheres; $(c)$ that they were nomenclatural type cultures or, at least, reference strains deposited in recognized collections. The strains chosen as satisfying these criteria are listed in Table 1.

Table 1. Organisms used in this work

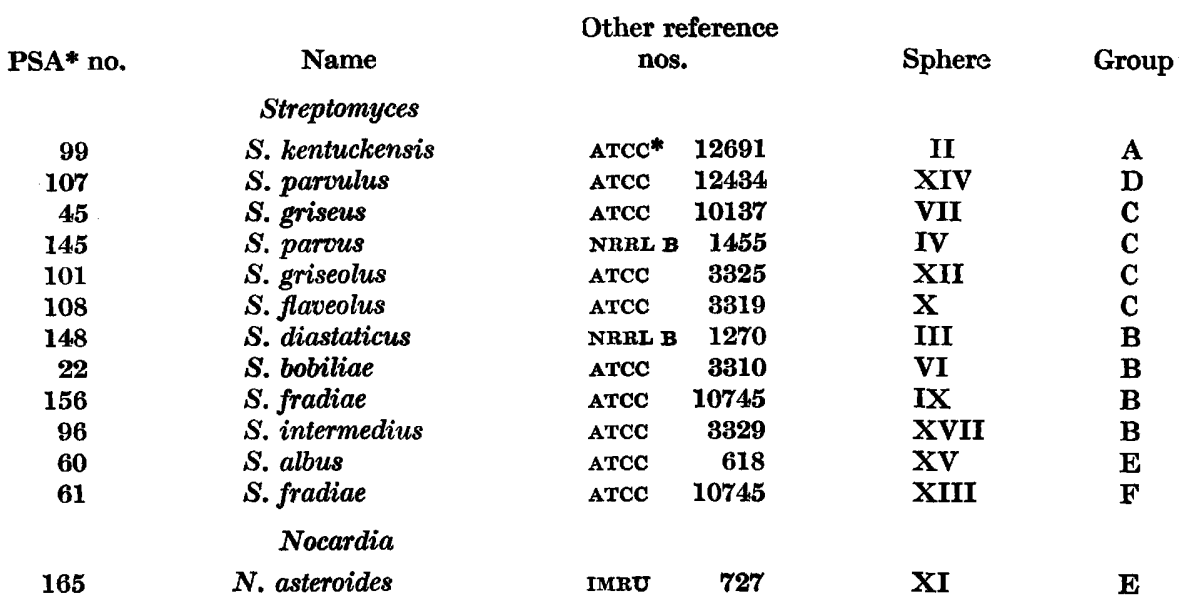

* ATCC = American Type Culture Collection. NRRL = North Regional Research Laboratory, Peoria, Ill., U.S.A. IMRU = Institute of Microbiology, Rutgers University, N.J., U.S.A. PSA = Progetto Sistematica Actinomiceti, Università Statale, Milano, Italia.

See the catalogue: The Culture Collection of the Progetto Sistematica Actinomiceti, 1962, and Silvestri et al. 1962.

Cultivation of organisms. Strains were inoculated with a wire-loop from slope cultures into $250 \mathrm{ml}$. flasks with an anti-vortex baffle containing $70 \mathrm{ml}$. of a liquid medium composed of: Bacto-Peptone (Difco) 5 g.; Bacto-Yeast Extract (Difco) 3 g.; glucose, 10 g.; Bacto-Casitone (Difco) 1 g.; Bacto-Beef Extract 2 g.; tap water 11. (For the Nocardia strain, better growth resulted with Bacto-Peptone and BactoCasitone replaced by Peptone and Caseina, 'Costantino', respectively.) Flasks were incubated at $30^{\circ}$ on an agitator for $48-60 \mathrm{hr}$. Subcultures were then made into the same medium by transferring $0.5 \mathrm{ml}$. samples of fully grown stationary phase culture into several flasks which were re-incubated for $24-\mathbf{3 0} \mathbf{~ h r}$. By this procedure growth as pellets was generally avoided and the cultures were in the logarithmic phase when the mycelia were collected by Buchner filtration or centrifugation. From 5 to $10 \mathrm{~g}$. (wet weight) of mycelia were used for each DNA preparation.

Preparation of DNA specimens. The procedure of Marmur (1961) was followed. 
Particular attention had to be paid to render optimal the lysis by lysozyme and sodium lauryl sulphate. Incubation with lysozyme was continued for 2-3 hr. but suspensions, though becoming viscous, did not become transparent until the detergent was added. Nocardia asteroides was normally resistant to lysozyme, but partial lysis was induced by pretreating $25 \mathrm{ml}$. suspension with $0.5 \mathrm{ml}$. ethane thiol $\left(\mathrm{C}_{2} \mathrm{H}_{5} \mathrm{SH}\right)$, overnight in the cold with agitation. According to $\mathrm{Dr}$ M. Mandel (personal communication) 2-mercapto-ethanol, $\mathrm{CH}_{2}(\mathrm{OH}) \mathrm{CH}_{2} \mathrm{SH}$, is probably more efficient in uncovering lysozyme-sensitive sites. Final isopropanol precipitates were fibrous in most cases and were stored in the dry state.

Table 2. Solutions used to determine the effect of ionic strength and $p H$ value on $T_{m}$ value with $D N A$ from Streptomyces bobiliae

\begin{tabular}{|c|c|c|c|c|c|c|c|c|}
\hline Soln. & $\begin{array}{c}\mathrm{KH}_{2} \mathrm{PO}_{4} \\
0.2 \mathrm{M} \\
(\mathrm{ml} .)\end{array}$ & $\begin{array}{c}\mathrm{Na}_{2} \mathrm{HPO}_{4} \\
0.2 \mathrm{M} \\
(\mathrm{ml} .)\end{array}$ & $\begin{array}{l}\text { EDTA } \\
0 \cdot 1 \mathrm{M} \\
\text { (ml.) }\end{array}$ & $\begin{array}{l}\text { Diluted } \\
\text { to } \\
\text { (ml.) }\end{array}$ & $\begin{array}{l}\text { Molarity } \\
\mathbf{P O}_{4}{ }^{3-} \\
(\mathbf{M})\end{array}$ & $\begin{array}{c}\text { pH } \\
\text { value }\end{array}$ & $\begin{array}{l}\text { Specific } \\
\text { conductance } \\
\times 10^{-3} \\
\text { mho }\end{array}$ & $\begin{array}{l}\boldsymbol{T}_{m} \\
\left({ }^{\circ}\right)\end{array}$ \\
\hline 1 & $2 \cdot 5$ & $2 \cdot 5$ & 10 & 200 & 0.005 & 6.7 & 0.831 & $75 \cdot 6$ \\
\hline 2 & $2 \cdot 5$ & 2.5 & 10 & 100 & 0.01 & 6.8 & 1.570 & $80 \cdot 5$ \\
\hline 3 & $2 \cdot 5$ & $2 \cdot 5$ & 10 & 50 & 0.02 & $6 \cdot 7$ & $2 \cdot 979$ & $85 \cdot 8$ \\
\hline 4 & $2 \cdot 5$ & $2 \cdot 5$ & 10 & 25 & 0.04 & $6 \cdot 7$ & $5 \cdot 590$ & $90 \cdot 8$ \\
\hline 5 & 4.5 & 0.5 & 10 & 100 & 0.01 & $5 \cdot 85$ & $1 \cdot 250$ & $76 \cdot 5$ \\
\hline 6 & $3 \cdot 5$ & 1.5 & 10 & 100 & 0.01 & $6 \cdot 40$ & $1 \cdot 440$ & $79 \cdot 25$ \\
\hline 7 & 1.5 & 3.5 & 10 & 100 & 0.01 & $7 \cdot 10$ & $1 \cdot 720$ & $81 \cdot 6$ \\
\hline 8 & 0.5 & $4 \cdot 5$ & 10 & 100 & 0.01 & $7 \cdot 50$ & 1.923 & $81 \cdot 8$ \\
\hline
\end{tabular}

Determination of $T_{m}$ values. Solutions containing 10-20 $\mu \mathrm{g}$. DNA $/ \mathrm{ml}$. were heated in a Beckman DU spectrophotometer fitted with thermal spacers (Marmur \& Doty, 1962) and the increase in extinction on denaturation of the DNA (hyperchromic effect) observed. An initial reading was made at $25^{\circ}$ and then, from $3-4^{\circ}$ before the onset of denaturation to $2-3^{\circ}$ after it had terminated, extinction readings were made at $1^{\circ}$ intervals, the temperature being raised at the rate of about $1^{\circ} / 10 \mathrm{~min}$. $T_{m}$ value is defined as the mid-point (50\%) of the hyperchromic effect.

Solvents. The \% GC content of a Streptomyces DNA has been reported to be in the order of 70-74\% (Belozersky \& Spirin, 1960; Marmur \& Doty, 1962) and therefore the $\boldsymbol{T}_{m}$ determination in the usual solvent SSC (standard saline citrate; $0.15 \mathrm{M}$ $\mathrm{NaCl}+0 \cdot 015 \mathrm{M}-\mathrm{Na}_{3}$ citrate, $\mathrm{pH} \mathrm{7 \cdot 0}$ ) requires temperatures higher than $100^{\circ}$ (Marmur \& Doty, 1962). Use has therefore to be made of more dilute solvents. It is reported in the literature (e.g. Ts'o, Helmkamp \& Sander, 1962), that the $T_{m}$ value is proportional to the logarithm of the ionic strength of the solvent and that, with SSC solvent, the $\mathrm{pH}$ value does not influence the $T_{m}$ value within the range $\mathrm{pH} \mathrm{5 \cdot 5-8 \cdot 5}$. Two sets of solutions were prepared (Table 2) to determine the effect on $T_{m}$ value of changing ionic strength ( $\mathrm{pH}$ constant) and of changing $\mathrm{pH}$ value in a region of an ionic strength lower than that of SSC solvent (molarity being constant). Specific conductance of solutions was determined with a Philips Conductivity Bridge, model GM 4249. By plotting $T_{m}$ values against the logarithm of specific conductance (Fig. 1) it is seen that the first four solutions, changing ionic strength, $\mathrm{pH}$ constant, fall on a straight line. With $0.01 \mathrm{M}-\mathrm{PO}_{4}{ }^{3-}, \mathrm{pH}$ changing, the indifference range of $\mathrm{pH}$ values was narrower than that reported for SSC solvent, since solutions at pH 6.4 and $7 \cdot 5$ already departed from the straight line. During these experiments 
it was noticed that the hyperchromic effect is also influenced by ionic strength. A quadratic relationship was found. The more dilute the solvent the less was the hyperchromic effect (e.g. in solution 1 the hyperchromic effect in duplicate samples was 23.1 and $21.9 \%$, whereas in solution 4 it was $27 \cdot 2$ and $27.9 \%$ ) (Fig. 2). The degree of hyperchromicity is, however, less reproducible than $T_{m}$ in replicate experiments. The hyperchromicity varies with conductance according to the following parabolic function:

$$
\% \text { hyperchromicity }=22 \cdot 40-0 \cdot 23 \log x+9 \cdot 74(\log x)^{2},
$$

where $x$ is the specific conductance of the solution.

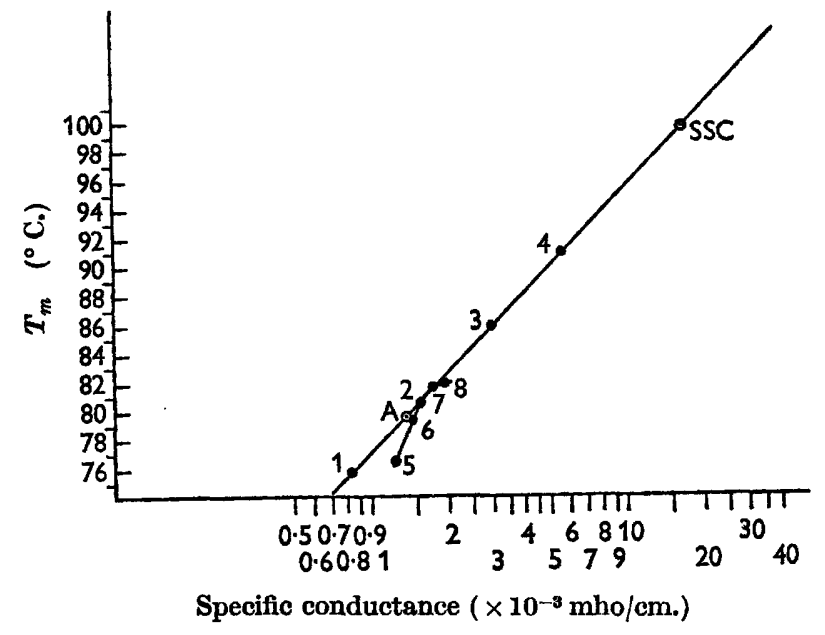

Fig. 1

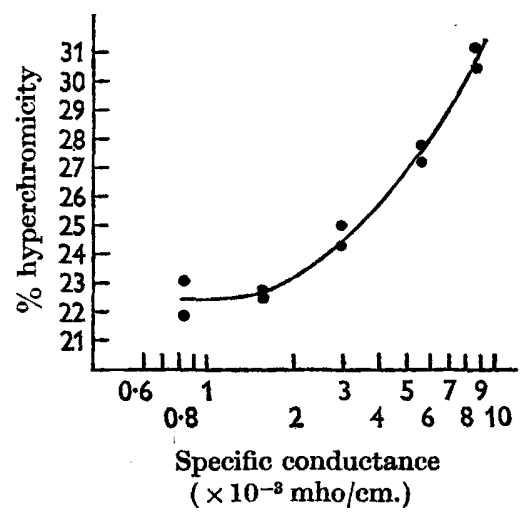

Fig. 2

Fig. 1. The relationship between $T_{m}$ values and ionic strength (DNA from Streptomyces bobiliae). Solvents $1-8$, see Table 2 . SSC = standard saline citrate solvent. $A=$ phosphate solvent used for $\boldsymbol{T}_{m}$ determinations.

Fig. 2. The relationship between the hyperchromic effect and ionic strength. DNA from Streptomyces bobiliae, duplicate samples.

The solvent finally chosen, as giving $T_{m}$ values $20^{\circ}$ less than the SSC solvent, was: $\mathrm{Na}_{2} \mathrm{HPO}_{4}, 0.2 \mathrm{M}, 2.5 \mathrm{ml} .+\mathrm{NaH}_{2} \mathrm{PO}_{4}, 0.2 \mathrm{M}, 2.5 \mathrm{ml}$. EDTA, $0.01 \mathrm{M}, 10 \mathrm{ml}$; diluted to $100 \mathrm{ml}$; $\mathrm{pH} \mathrm{6.8}$; specific conductance $1.345 \times 10^{-3} \mathrm{mho}$. Under our conditions, the specific conductance of SSC solvent was $16 \times 10^{-3}$ mho and, from Fig. 1, the above phosphate solution (indicated by $A$ in Fig. 1) should yield $T_{m}$ values $20 \cdot 1^{\circ}$ less than in SSC solvent.

Buoyant density. The technique of Meselson, Stahl \& Vinograd (1957) was used with Escherichia coli B DNA as reference $\left(1710 \mathrm{~g} . / \mathrm{cm} .{ }^{3}\right)$. $\mathrm{CsCl}$ was obtained from Merck(Darmstadt; ELH grade) and used with nofurther purification. Runs were made in a Spinco model $\mathrm{E}$ analytical ultracentrifuge and lasted $24 \mathrm{hr}$ at $44,770 \mathrm{rev} . / \mathrm{min}$.

\section{RESULTS}

Thermal denaturation. We previously reported on the reproducibility of $T_{m}$ values (Hill \& Silvestri, 1963); in the present work the largest difference obtained with duplicate samples was $0 \cdot 25^{\circ}$ with the same batch of solvent. $T_{m}$ values for the various 


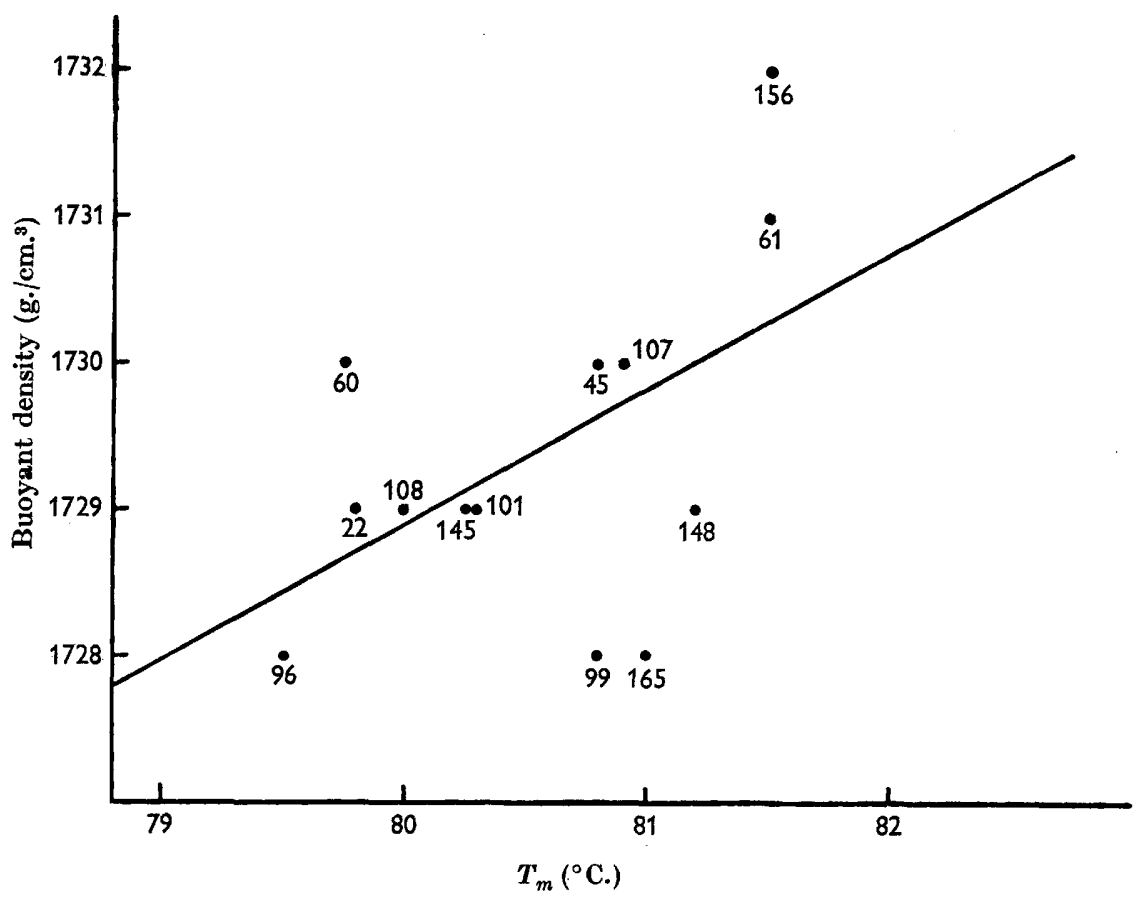

Fig. 8. The correlation between $T_{m}$ and buoyant density. Numbers in the figure refer to the organisms in Table 1. $r=0.502, n=11, P=0.07$.

Table 3. $\%$ GC from $T_{m}$ and buoyant density $(\rho)$ values of various $D N A$ preparations
(1)
(2)
(3)
(4)

(5)

Strain

$\begin{array}{ll}T_{m} & \% \mathbf{G C} \\ \left(^{\circ}\right) & \text { from } T_{m}\end{array}$

g. $/ \mathrm{cm}$.

$\%$ GC

from $\rho$

Difference

\section{Streptomyces}

S. kentuckensis 99

S. paroulus 107

$80 \cdot 8$

$80 \cdot 9$

$S$. griseus

45

$80 \cdot 8$

$76 \cdot 8$

$7 \boldsymbol{7} \cdot 2$

$76 \cdot 8$

$1 \cdot 728$

$1 \cdot 730$

$80 \cdot 25$

$75 \cdot 5$

$1 \cdot 730$

$1 \cdot 729$

$75 \cdot 6$

$1 \cdot 729$

80.0

$\mathbf{7 4} \cdot 8$

$1 \cdot 729$

S. flaveolus 108

$81 \cdot 2$

$77 \cdot 8$

$1 \cdot 729$

$79 \cdot 8$

74.4

$1 \cdot 729$

S. bobiliae

22

$81 \cdot 5$

S. intermedius $\quad 96$

$79 \cdot 5$

S. albus

$79 \cdot 75$

$78 \cdot 5$

$73 \cdot 6$

$74 \cdot 3$

$1 \cdot 732$

$1 \cdot 728$

$1 \cdot 730$

$81 \cdot 5$

$78 \cdot 5$

$1 \cdot 731$

$69 \cdot 4$

$71 \cdot 4$

$71 \cdot 4$

$70 \cdot 4$

$70 \cdot 4$

$70 \cdot 4$

$70 \cdot 4$

$70 \cdot 4$

$73 \cdot 4$

$69 \cdot 4$

71.4

$72 \cdot 4$ 2-4 $(\%)$

\section{Nocardia}

N. asteroides 165

$81 \cdot 0$

$77 \cdot 3$

$1 \cdot 728$

$69 \cdot 4$

$$
\begin{array}{r}
+7 \cdot 4 \\
+5 \cdot 8 \\
+5 \cdot 4 \\
+5 \cdot 1 \\
+5 \cdot 2 \\
+4 \cdot 4 \\
+7 \cdot 4 \\
+4 \cdot 0 \\
+5 \cdot 1 \\
+4 \cdot 2 \\
+2 \cdot 8 \\
+6 \cdot 1
\end{array}
$$

Notes. Col. 1 in 0.01 $\mathrm{M}_{-} \mathrm{PO}_{4}+0 \cdot 001 \mathrm{~m}$-EDTA (pH 6.8). Col. $2 T_{m}=49 \cdot 3+0 \cdot 41(\mathrm{GC})$. Col. 3 relative to Escherichia coli в NDA $=1 \cdot 710 \mathrm{~g} . / \mathrm{cm} .^{3}$ Col. $4 \rho=1 \cdot 660+0 \cdot 098$ (GC). 
samples are listed in column 1, Table 3, together with \% GC calculated (column 2) by means of the linear relationship (Marmur \& Doty, 1962): $T_{m}=49 \cdot 3+0 \cdot 41$ (GC).

Buoyant density, $\rho$. Values are listed in column 3, Table 3, together with \% GC calculated (column 4) by means of the linear relationship (Schildkraut et al. 1962): $\rho=1 \cdot 660+0 \cdot 098($ GC) .

Correlation between $T_{m}$ and buoyant density values. The correlation coefficient between the two sets of values was calculated, $r=0.502, n=11, P=0.07$ (Fig. 3). The correlation coefficient between $T_{m}$ values (Hill \& Silvestri, 1963) in an $\mathrm{Na}_{2} \mathbf{H P O}_{4}$ solvent, adjusted to $\mathrm{pH} 7.0$ with $\mathrm{NaOH}$, gave the following results: $r=\mathbf{0} \cdot 6275$, $n=10, P=0.03$.

The better correlation of the previously published data can be attributed to the fact that then determinations were conducted with the same batch of solvent. Changing batches with such dilute solvents introduces another source of variance.

Difference in \% GC according to $\boldsymbol{T}_{m}$ and buoyant density values. In Table 3 , column 5 , the differences in \% GC calculated from $T_{m}$ and from buoyant density are recorded. Those calculated from $\boldsymbol{T}_{m}$ were always higher than those calculated from buoyant density, the differences ranging from a minimum of $2 \cdot 8 \%$ to a maximum of $7 \cdot 9 \%$; the average difference was $5 \cdot 46 \%$ GC.

In the studies of Marmur \& Doty (1962) and Schildkraut et al. (1962), only one streptomycete DNA (from Streptomyces viridochromogenes) was examined for $\boldsymbol{T}_{m}$ and buoyant density. These authors too found a difference between \% GC calculated from $T_{m}(74 \%)$ and from buoyant density $(70 \%)$. Chromatographic analysis of the bases yielded a \% GC of $\mathbf{7 3 \cdot 8} \%$ for this species (Belozersky \& Spirin, 1960). Schildkraut et al. (1962) discussed several explanations for this discrepancy, perhaps the most important of which was the possible existence of bases other than the usual four.

With respect to our data, the range of $\% \mathrm{GC}$ calculated from $T_{m}$ values using the equation of Marmur \& Doty (1962) is from a minimum of $73.6 \%$ to a maximum of $78.5 \%$.

Range of $\%$ GC within Streptomyces. The $2^{\circ}$ difference between the minimum $T_{m}$ value (strain 96 Streptomyces intermedius) and the maximum $\boldsymbol{T}_{m}$ (strains 61 and 156, both $S$. fradiae) corresponds to a $\%$ GC range of $4.9 \%$. Again, the $\%$ GC from the buoyant density data is $4 \%\left(0.004 \mathrm{~g} . / \mathrm{cm} .{ }^{3}\right)$ difference between the minimum buoyant density (strains 99, 96, 165) and the maximum (strain 156).

\section{DISCUSSION}

The range of \% GC in Streptomyces seems to be very restricted. Jones \& Bradley (1963), with fewer strains, found a yet narrower range. Though the difference between maximum and minimum \% GC is large enough to allow a clear distinction between the extreme strains, the fact that there is a continuous progression of base composition precludes an attempt to make taxonomic divisions on the basis of overall \% GC composition alone. Only one strain of Nocardia was included in this study, but apparently distinction between the two genera on this basis alone seems impossible. This continuity of DNA composition within a genus was also observed by De Ley \& Schell (1963) in acetic acid bacteria. Given that the maximum difference in $\%$ GC was about $4 \%$, then even the strains most distant from one 
another could have in common many DNA molecules (Sueoka, 1961). Broadspectrum actinophages are known such as 1091 (Silvestri et al. 1962) which are active against strains which differ by as much as $2 \%$ GC. Furthermore, reports exist in the literature of transformation between Streptomyces aureofaciens and $S$. griseus (Jarai, 1961), of heterokaryosis between $S$. cyaneus and S. griseus (Bradley \& Lederberg, 1956) and of recombination between S. rimosus, S. coelicolor and $S$. aureofaciens (Alacevic, 1963). On the basis of the present data concerning DNA base composition, phage sensitivity and genetic exchange, it seems legitimate to doubt of the existence of isolated species within the Streptomyces taxon, which is presently considered to merit a generic rank. It is probable that the process of 'splitting' has been carried too far. By phenetic taxometric studies it is easier to resolve the genus Streptomyces into distinguishable groups. However, in view of the available facts, we are doubtful whether the phenetic groups (spheres) individuated by electronic computer could be properly considered species deserving distinct binomials. On the other hand, the relative scarcity of molecular and genetic data within the genus does not permit a more definite conclusion at present, neither an evaluation of the taxonomic rank of the phenetic taxa.

It is interesting to note that strain 99 Streptomyces kentuckensis, which is in the middle of the \% GC range found here within the genus, occupied also a central position in the phenetic hyperspace of our previous taxometric study (Silvestri et al. 1962). This organism is near the geometric centre of the second sphere, which is itself located in a very central position in respect to the entire system.

We are indebted to Professors P. Caldirola and R. Fieschi for allowing us to utilize a spectrophotometer of the solid state laboratory of the Institute of Physics of the University of Milan. The authors are also indebted to Professors P. Polli and L. Di Mayorca. Ultracentrifuge runs were carried out by Mr G. Conti.

This paper is publication no. 14 of the Progetto Sistematica Actinomiceti supported by assignesione no. 04/80/4/3082 of the Consiglio Nazionale delle Ricerche.

\section{REFERENCES}

Alacevic, M. (1963). Interspecific recombination in Streptomyces. Nature, Lond. 197, 1323.

Belozersky, A. N. \& Spirin, A. S. (1960). In The Nucleic Acids, vol. 3, p. 147. Ed. by E. Chargaff \& J. N. Davidson. London and New York: Academic Press.

Bradley, S. G. \& Lederberg, J. (1956). Heterokaryosis in Streptomyces. J. Bact. 72, 219.

DE LEY, J. \& Schell, J. (1963). Deoxyribonucleic acid base composition of acetic acid bacteria. J. gen. Microbiol. 33, 243.

Hill, L. R. \& Silvestri, L. G. (1963). Rapporto delle basi del DNA e analisi tassometrica di alcuni streptomiceti. Boll. Soc. it. Biol. sper. 39, 1864.

JARAI, M. (1961). Transformation in Streptomyces. Acta microbiol. Acad. Sci. hung. 8, 81.

Jones, L. A. \& Bradley, S. G. (1963). Thermal denaturation of deoxyribonucleic acid from actinomycetes and actinophages. Bact. Proc. p. 148.

LeE, K. Y., Wahl, R. \& Barbu, E. (1956). Contenu en bases puriques et pyrimidiques des acides désoxyribonucléiques des bactéries. Annls Inst. Pasteur, Paris, 91, 212.

Marmur, J. (1961). A procedure for the isolation of deoxyribonucleic acid from microorganisms. J. mol. Biol. 3, 208. 
Marmur, J. \& Doty, P. (1962). Determination of the base composition of deoxyribonucleic acid from its thermal denaturation temperature. J. mol. Biol. 5, 109.

Marmur, J., Falkow, S. \& Mandel, M. (1963). New approaches to bacterial taxonomy. Ann. Rev. Microbiol. 17, 329.

Meselson, M., Stahi, F. W. \& Vinograd, J. (1957). Equilibrium sedimentation of macromolecules in density gradients. Proc. nat. Acad. Sci., Wash. 43, 581.

Schildkradt, C. L., Marmur, J. \& Doty, P. (1962). Determination of the base composition of deoxyribonucleic acid from its buoyant density in $\mathrm{CsCl}$. J. mol. Biol. 4, 430.

Silvestri, L. G., Turri, M., Hrux, L. R. \& Gilardi, E. (1962). A quantitative approach to the systematics of actinomycetes based on overall similarity. In Microbial Classification. Symp. Soc. gen. Microbiol. 12, 333.

Sueoka, N. (1961). Variation and heterogeneity of base composition of deoxyribonucleic acids: a compilation of old and new data. J. mol. Biol. $3, \mathbf{3 1}$.

Ts'o, P. O. P., Helmkamp, G. K. \& Sander, C. (1962). Interaction of nucleosides and related compounds with nucleic acids as indicated by the change of helix-coil transition temperature. Proc. nat. Acad. Sci., Wash. 48, 686. 